Águas Subterrâneas (2015) 29(2): 175-190.

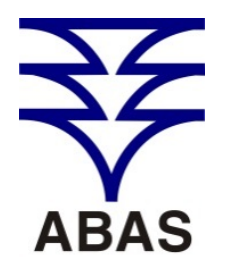

ASSOCIAC,ÁO BRASILEIRADE www.abas.org

\title{
SIMULAÇÃO NUMÉRICA DE FLUXO DE ÁGUAS SUBTERRÂNEAS DO AQUÍFERO RIO CLARO, PORÇÃO NORDESTE DO MUNICÍPIO DE RIO CLARO, SP
}

\author{
NUMERICAL SIMULATION OF GROUNDWATER FLUX OF THE RIO \\ CLARO AQUIFER, NORTHEAST REGION OF RIO CLARO, SP
}

Guilherme Emidio Horta Nogueira ${ }^{1}$; Chang Hung Kiang ${ }^{2}$

Artigo recebido em: 23/02/2015 e aceito para publicação em: 22/06/2015.

DOI: http://dx.doi.org/10.14295/ras.v29i2.28304

\begin{abstract}
In the UNESP campus area in Rio Claro - SP, the water supply is stemmed solely from the local aquifer, consisting of sandy-silt Cenozoic sediments of the Rio Claro Formation. The mainly objective of this work was to expand the understanding of the Rio Claro Aquifer through the review of the conceptual model and construction of a numerical flow model, using the Finite Element Method as solution. The results obtained after the steady-state and transient simulations, show that the lithological and hydrous heterogeneity of the aquifer unit result in a lower average specific storage; show also that the local drainages act as discharge zones and the campus and neighbors area act as area of recharge. The hydraulic conductivity values vary from $10^{-6}$ and $10^{-4} \mathrm{~m} / \mathrm{s}$ and the ratio recharge/precipitation was stipulated in $13 \%$. For a hypothetical doubling the rate of exploitation of wells, as well as for the partial or total removal of recharge, it was noticed large change in sensitivity of the model and large impact on the aquifer.
\end{abstract}

Keywords: Hydrological Modeling. Rio Claro Aquifer. Finite Elements. FeFlow.

Resumo: No campus da UNESP em Rio Claro, SP, o abastecimento hídrico provém unicamente do aquífero local, constituído por sedimentos cenozoicos areno-siltosos da Formação Rio Claro. O principal objetivo deste trabalho foi a ampliação do entendimento do Aquífero Rio Claro, por meio da revisão do modelo conceitual e construção de modelo numérico de fluxo, utilizando o Método de Elementos Finitos como solução. Os resultados obtidos com as simulações em regime permanente e transiente mostram que a heterogeneidade litológica e hídrica da unidade aquífera resulta em baixo armazenamento específico médio; evidenciam também que as drenagens funcionam como zonas de descarga, e o território do câmpus e circunvizinhanças como área de recarga. A condutividade hidráulica varia entre $10^{-6} \mathrm{~m} / \mathrm{s}$ e $10^{-4} \mathrm{~m} / \mathrm{s}$, e a razão recarga/precipitação foi estimada em $13 \%$. Para uma hipotética duplicação na taxa de explotação dos poços, bem como para a supressão parcial ou total da recarga, notou-se grande alteração na sensibilidade do modelo e grande impacto no aquífero.

Palavras-chave: Modelagem Hidrogeológica. Aquífero Rio Claro. Elementos Finitos. FeFlow.

\section{INTRODUÇÃO}

Águas subterrâneas têm ganhado maior importância e reconhecimento à medida que fontes superficiais não têm sido suficientes para a atual e crescente demanda. Nesse contexto, modelos hidrogeológicos numéricos têm se mostrado especialmente úteis ao estudo e representação de formações aquíferas complexas, à compreensão dos processos hidrodinâmicos e à melhor gestão desses recursos. Aplicações de modelos numéricos em hidrogeologia podem ser vistos, por exemplo, em
Alberto (2005), Teramoto (2007) e Stollberg (2013).

Por definição, modelos são ferramentas que representam, de forma simplificada, alguns processos naturais (FREEZE e CHERRY, 1979). Em hidrogeologia, a aplicação de modelos numéricos permite avaliar e identificar incertezas e características de uma unidade aquífera. Uma vez que o modelo calibrado seja representativo, ele pode amparar futuras pesquisas na área e ser utilizado na projeção de cenários hipotéticos.

$\mathrm{O}$ aquífero Rio Claro, localizado no

\footnotetext{
${ }^{1}$ Universidade Estadual Paulista - Júlio de Mesquita Filho (UNESP) (guilherme_ehn@hotmail.com)

${ }^{2}$ Professor Titular Instituto de Geociências e Ciências Exatas - Campus de Rio Claro, Departamento de Geologia Aplicada (chang@rc.unesp.br)
} 
município homônimo, é atualmente a única fonte para abastecimento hídrico do câmpus da UNESP na cidade. As particularidades e características desse aquífero, cujo conhecimento é fundamental para sua gestão, podem ser simplificadas e mais bem representadas por modelos numéricos computacionais.

Dessa forma, este estudo, calcado na aplicação de modelo numérico de fluxo pelo Método dos Elementos Finitos (MEF), teve como principal objetivo ampliar o conhecimento hidrogeológico do Aquífero Rio Claro, utilizando-se principalmente de informações existentes no câmpus da UNESP, onde a explotação do aquífero é ativa. Além disso, procurou-se refinar o entendimento da participação dos poços de bombeamento frente ao balanço hídrico final do sistema no período observado (setembro/2013 a setembro/2014).

A utilização de modelos numéricos pelo MEF em problemas relacionados ao fluxo de águas subterrâneas é relativamente recente, sobretudo em território nacional. Dessa forma, a contribuição à ampliação do uso da técnica e o seu melhor entendimento são objetivos complementares da presente pesquisa.

\section{CARACTERIZAÇÃO DA ÁREA}

A porção nordeste da cidade de Rio Claro (Figura 1), alvo do presente estudo, abrange o câmpus da UNESP, além de bairros residenciais e industriais. A região onde se insere é caracterizada como subtropical úmida, com duas estações bem definidas e chuvas concentradas entre os meses de novembro e março. As médias pluviométricas giram em torno de $1400 \mathrm{~mm} / \mathrm{ano}$, porém já foram registrados extremos de $730 \mathrm{~mm} / \mathrm{ano}$ e 2300 mm/ano (SigRH, 2014).

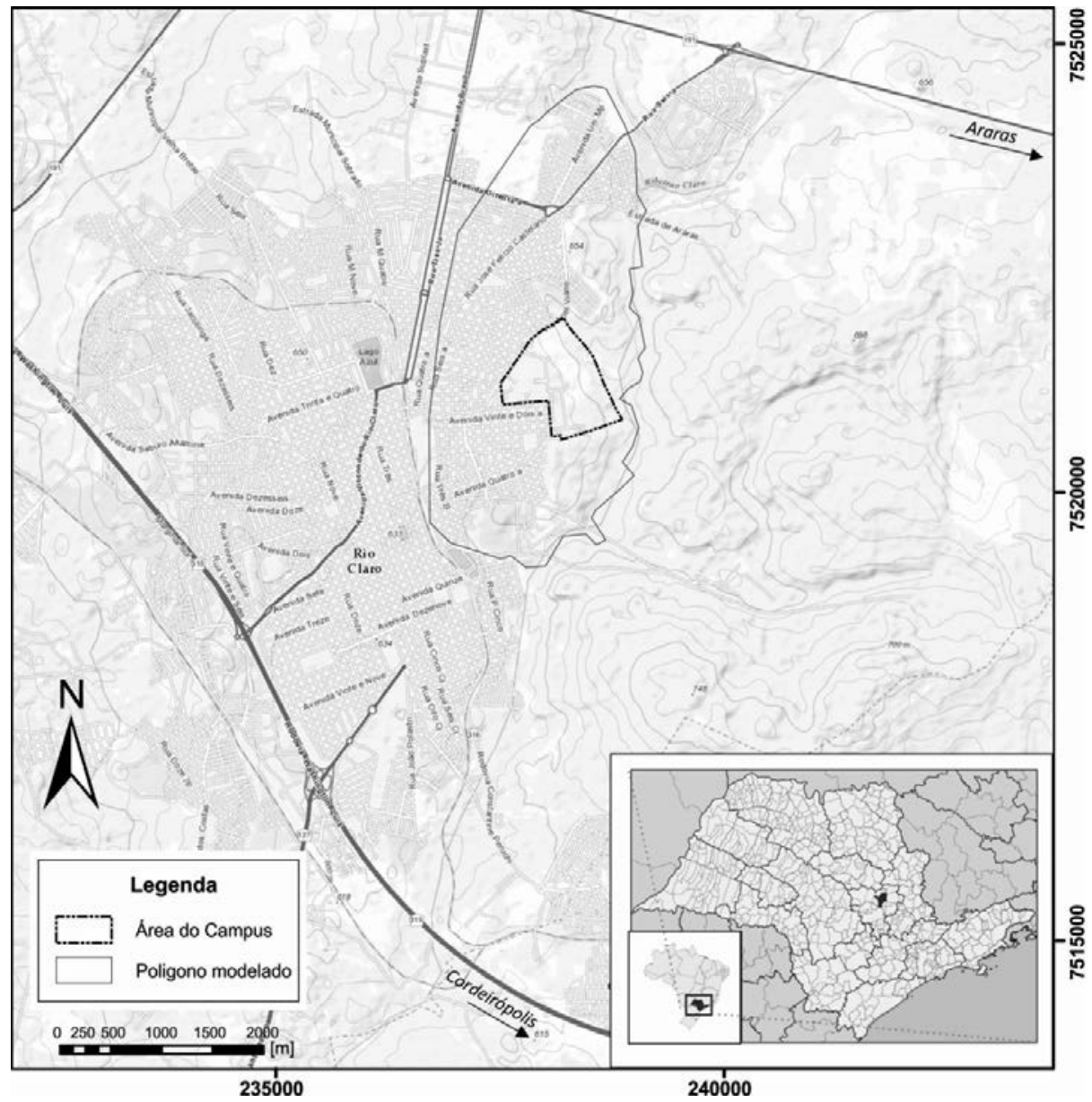

Figura 1 - Mapa de localização da área de estudo

Figure 1 - Location map of the study area 
Simulação numérica de fluxo de águas subterrâneas do aquífero rio claro, porção nordeste do município de Rio Claro, SP

O município de Rio Claro localiza-se a aproximadamente $190 \mathrm{~km}$ da cidade de São Paulo e está situado na Depressão Periférica Paulista, sobre sedimentos da Formação Rio Claro e rochas da Bacia do Paraná. Além da

Formação Rio Claro, afloram na região duas unidades litoestratigráficas da bacia - formações Corumbataí (Neopermiano) e Serra Geral (Eocretáceo) -, como pode ser visto no mapa geológico da área (Figura 2).

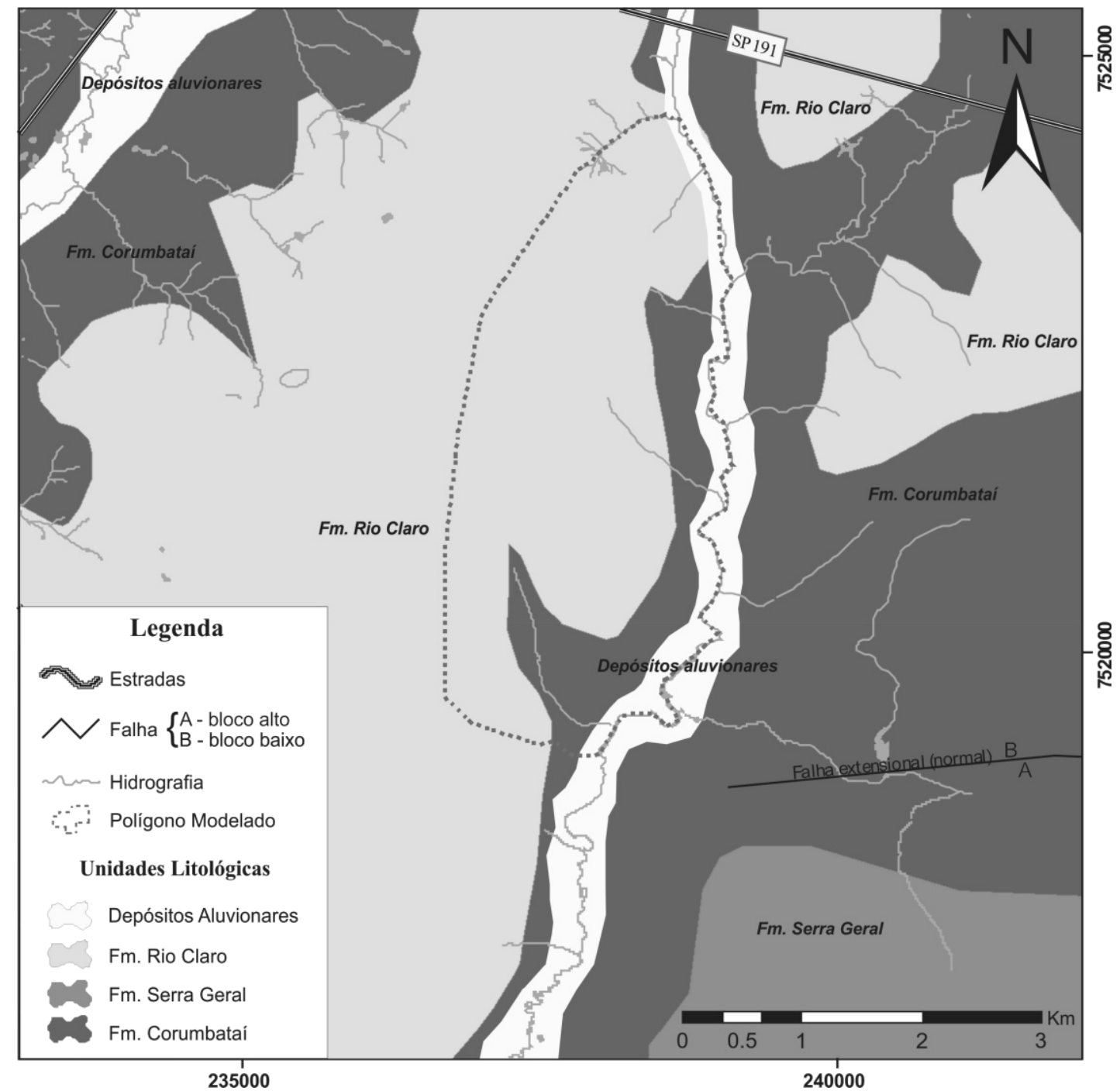

Figura 2 - Mapa geológico simplificado da região de Rio Claro, com a localização do polígono modelado (CPRM, 2002)

Figure 2 - Simplified geological map of Rio Claro area, with the location of the modeled polygon (CPRM, 2002)

O arcabouço geológico do Aquífero Rio Claro é constituído pela unidade litoestratigráfica homônima. A Formação Rio Claro é um dos depósitos mais expressivos formados durante o Cenozoico no estado de São Paulo (ZAINE, 2000). Constitui-se de areias mal selecionadas, com intercalações de siltes, lentes argilosas e níveis conglomeráticos, apresentando pouca litificação e profunda alteração pedoge- nética. Sua espessura média na região é de 30 m (PERINOTTO et al., 2006).

Seções colunares levantadas por Zaine (1994) e Perinotto et al. (2006) nas circunvizinhanças da área de estudo revelam alternância entre camadas arenosas e argilosas em toda a unidade e contato basal erosional com a Formação Corumbataí (Figura 3). 


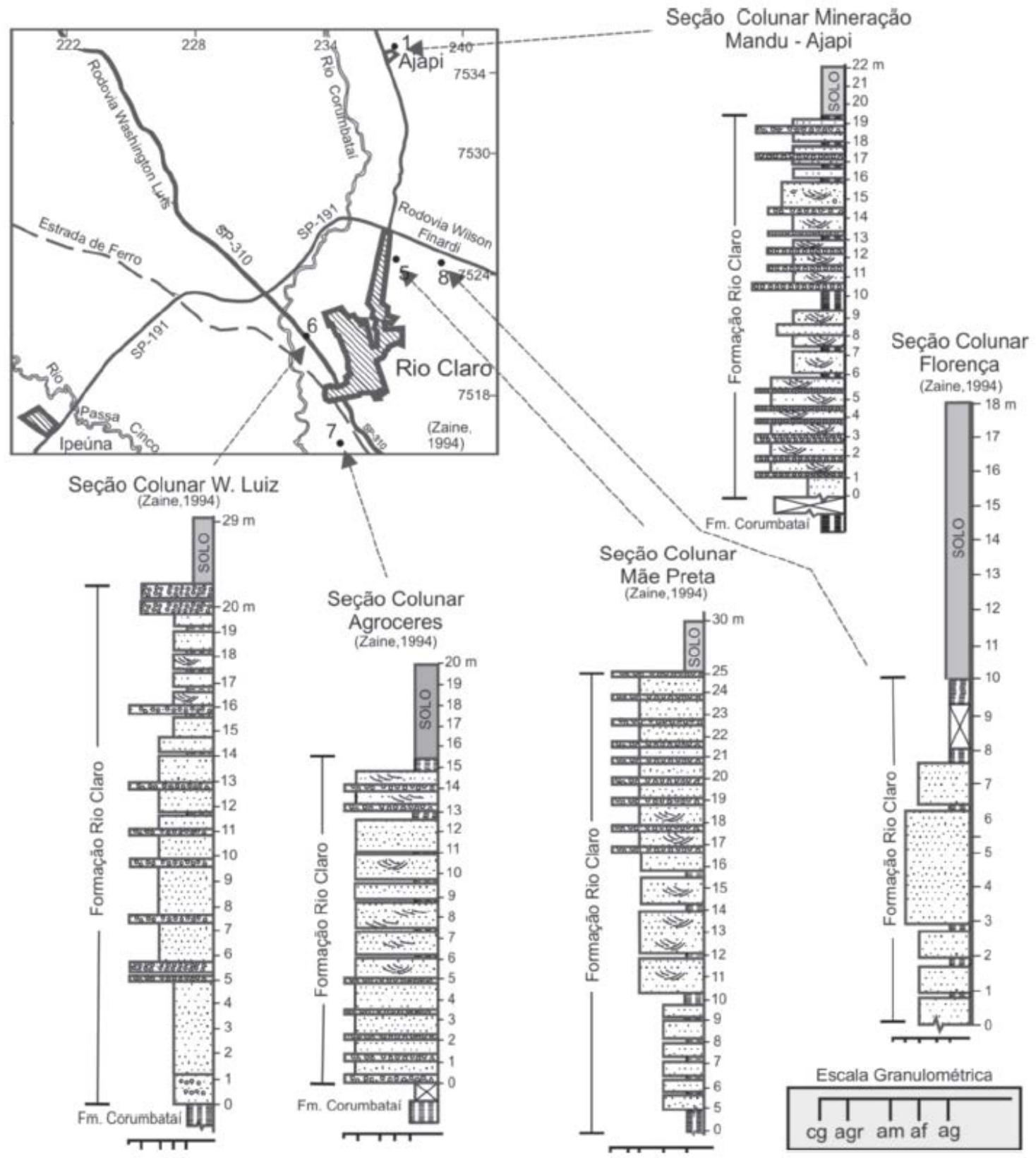

Figura 3 - Seções colunares levantadas por Zaine (1994) e Perinotto et al. (2006) nas proximidades da área de estudo. Notar alternância entre camadas arenosas e argilosas na unidade (Retirado de PERINOTTO et al., 2006)

Figure 3 - Colunar sections made by Zaine (1994) and Perinotto et al. (2006) near the study area. It is noticed the alternation of sandy and clay layers in the formation (source: PERINOTTO ET AL, 2006)

A Formação Corumbataí, unidade superior do Grupo Passa Dois na região, é composta predominantemente por lamitos, siltitos e argilitos de ambiente marinho raso. Na área, a unidade apresenta leve mergulho para sul. Mais raramente, a Formação Rio Claro assenta-se sobre a Formação Piramboia, composta por arenitos flúvio-eólicos do Triássico.

Rochas intrusivas de caráter básico, relacionadas à Formação Serra Geral, aparecem isoladas na forma de diques e soleiras intrudi- dos em rochas do Grupo Passa Dois e Formação Piramboia. As espessuras mensuradas desses corpos intrusivos variam desde poucos metros a mais de $200 \mathrm{~m}$.

\section{MATERIAIS E MÉTODOS}

Para a elaboração do modelo foram reunidas informações acerca dos litotipos e sua distribuição na área de estudo, dados de níveis d’água (NA) local, das características hidráuli- 
Simulação numérica de fluxo de águas subterrâneas do aquífero rio claro, porção nordeste do município de Rio Claro, SP

cas dos litotipos presentes e dos dados meteorológicos do período monitorado.

As informações litológicas foram obtidas, em sua maioria, a partir de estudos anteriores (teses, monografias e artigos de periódicos) e consultas a banco de dados e relatórios técnicos (Zaine, 1994, 2000; Oliva, 2006, Perinotto et al, 2006; SIAGAS/CPRM, 2014; SigRH, 2014). O comportamento do NA foi verificado em poços de monitoramento (PM) do câmpus da UNESP em Rio Claro, entre 09/09/2013 e 09/09/2014. As características hidráulicas foram obtidas a partir de ensaios de campo e em amostras coletadas de ensaio Standard Penetration Test (SPT) efetuado dentro do câmpus. Os dados meteorológicos foram obtidos da estação meteorológica do câmpus da UNESP.

Utilizando-se tais dados foram elaborados modelos numéricos em regime permanente e em regime transiente para simular o comportamento do fluxo no aquífero. O software utilizado foi o FEFLOW 6.1 ${ }^{\circledR}$, da DHI-WASY, que emprega o MEF para a solução matemática das equações do fluxo de águas subterrâneas.

O principio matemático do MEF é converter uma equação diferencial parcial (no caso, a que rege o fluxo de águas subterrâneas) em uma série de equações algébricas $\operatorname{com} n$ número de variáveis, assumindo assim uma solução aproximada para cada equação. Em hidrogeologia, o valor de carga hidráulica é a incógnita a ser resolvida (EL-KADI, 1995).

No modelo conceitual admite-se que o Aquífero Rio Claro constitui um aquífero livre e de caráter sedimentar, armazenando água em seus interstícios porosos e fissuras. As drenagens funcionam como zonas de descarga do aquífero, enquanto sua recarga se dá por águas pluviais. Oliva (2006) calculou a condutividade hidráulica da Formação Rio Claro, situando-a entre $10^{-7} \mathrm{~m} / \mathrm{s}$ e $10^{-4} \mathrm{~m} / \mathrm{s}$. A base impermeável do aquífero é definida pelo contato entre os arenitos da unidade aquífera e os lamitos sotopostos da Formação Corumbataí.

O desenvolvimento do trabalho foi pautado em quatro etapas, balizadas em fluxogramas de modelagem hidrogeológica elaborados por diversos autores como, por exemplo, Anderson e Woessner (1992) e Spitz e Moreno (1996). As etapas do trabalho foram as seguintes (Figura 4):

Etapa 1 - Monitoramento periódico do NA em poços de monitoramento existentes no câmpus da UNESP, bem como trabalho de campo para realização de ensaio SPT e coleta de amostras de calha;

Etapa 2 - Caracterização e obtenção de parâmetros hidráulicos a partir de testes slug e ensaios laboratoriais de amostras coletadas;

Etapa 3 - Elaboração e revisão do modelo conceitual com a integração dos dados reunidos da literatura e os dados coletados nas campanhas de campo;

Etapa 4 - Simulação numérica de fluxo por meio do MEF em regimes permanente e transiente, com o uso do software FEFLOW $6.1^{\circledR}$. 
NOGUEIRA, G.E.H.; KIANG, C.H.

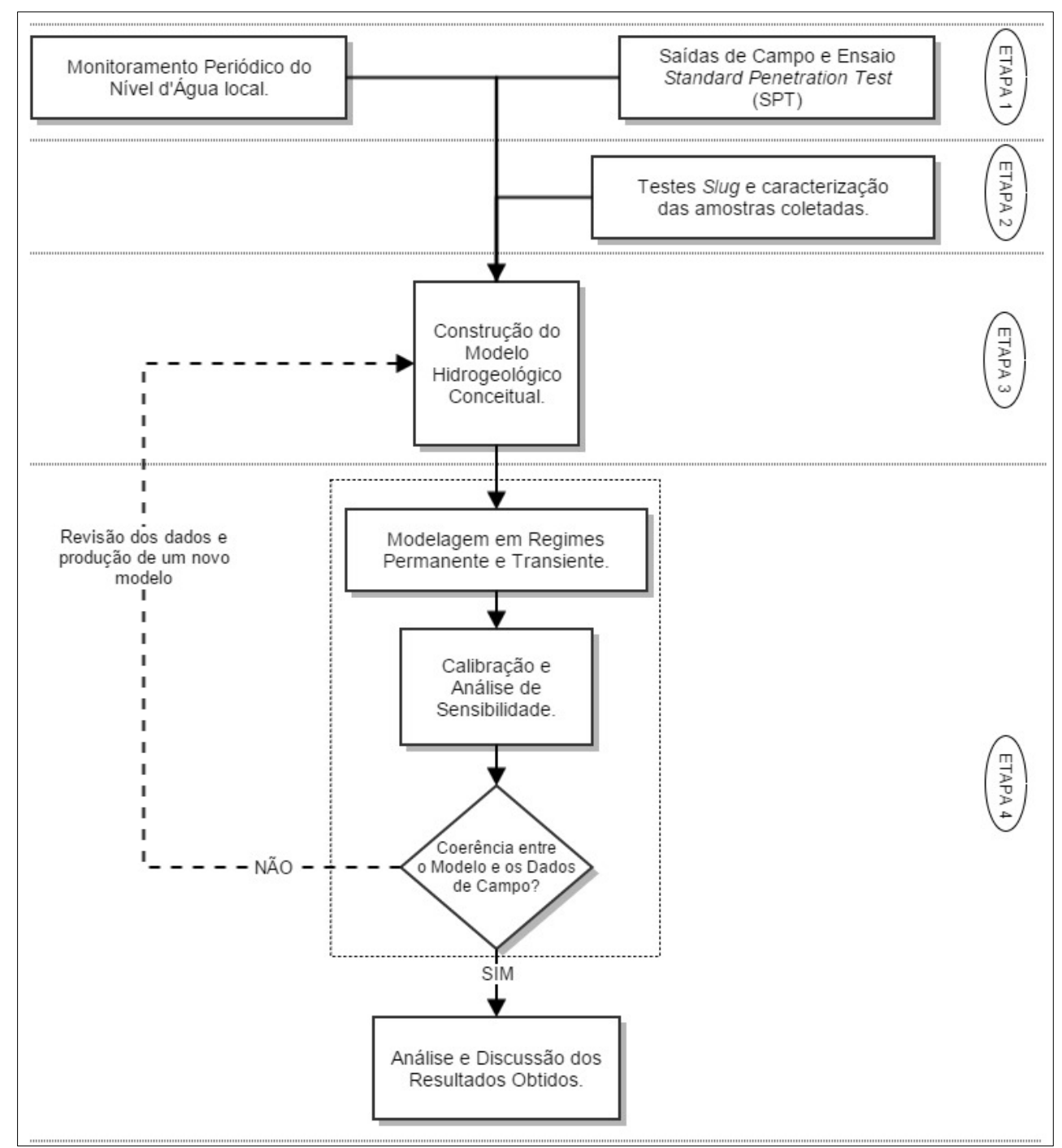

Figura 4 - Fluxograma das etapas de trabalho

Figure 4 - Methodological flowchart with the work steps

A caracterização hidrogeológica inicial utilizou-se dos valores de NA e de testes slug realizados nos PM. Amostras de calha do ensaio SPT foram coletadas para posterior análise e classificação. O banco de dados SIAGAS/CPRM foi consultado para aquisição e análise dos perfis de poços cadastrados na área. A localização dos poços e do ensaio SPT é exibida na Figura 5.

Os poços de monitoramento não apresentam distribuição regular na área, como seria recomendado para modelagem. Contudo, a utilização das demais informações trouxe maior representatividade ao conjunto de dados.

A profundidade final do ensaio SPT foi de $17 \mathrm{~m}$, atingindo o contato local entre as formações Rio Claro e Corumbataí. As amostras coletadas passaram por análise e classificação granulométrica para a obtenção de condutividade hidráulica pelo método indireto de Shepherd. 


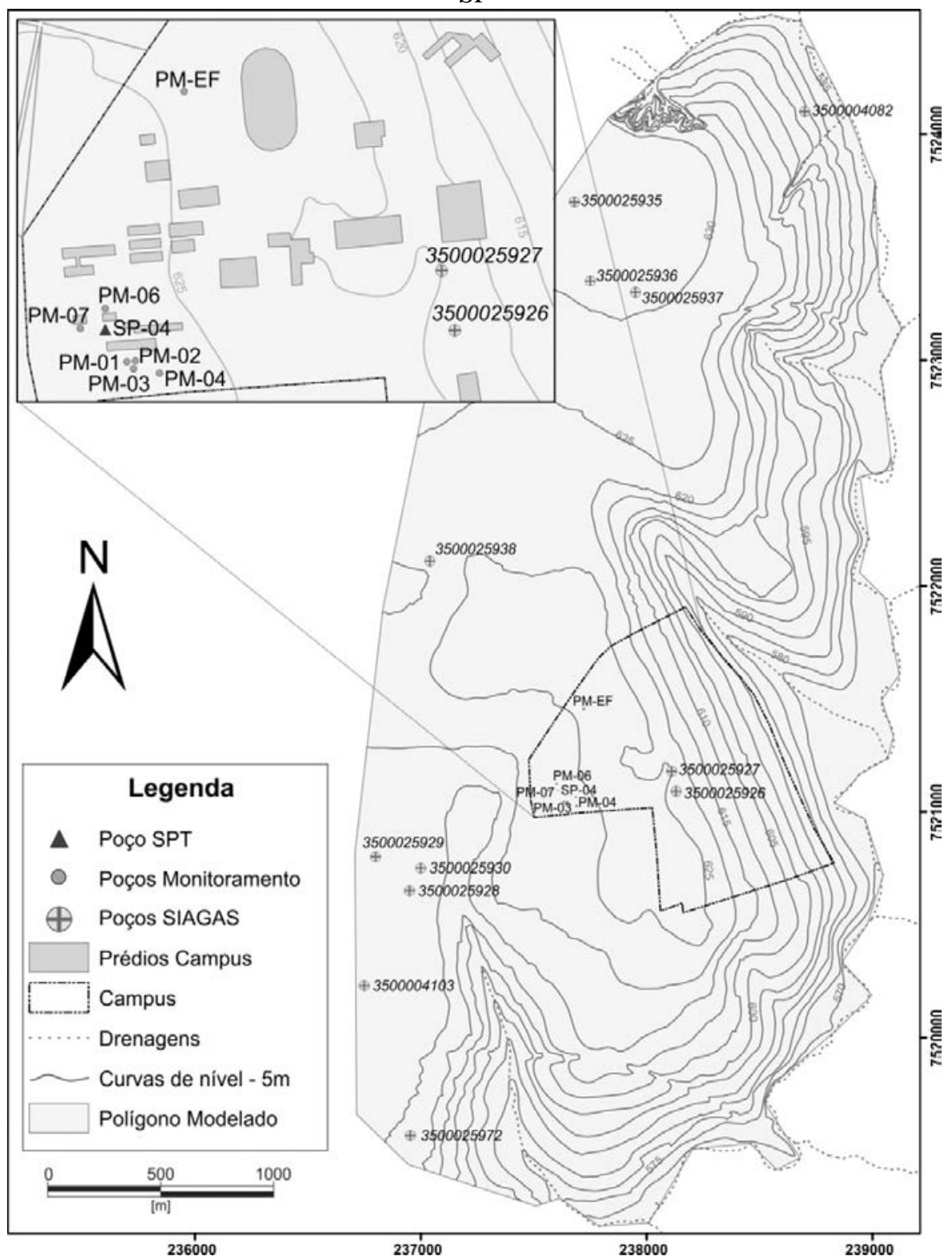

Figura 5 - Localização dos poços e do furo de ensaio SPT no campus da UNESP em Rio Claro. Os poços do SIAGAS/CPRM aparecem com seu respectivo código na figura

Figure 5 - Location of the wells and SPT test hole on the UNESP campus in Rio Claro. The SIAGAS/CPRM wells show their respective codes on the picture

\section{RESULTADOS E DISCUSSÕES} Após um ano de medidas diárias da carga fevereiro, quando o NA ascendeu apenas 0,5 m. hidráulica nos PM instalados no câmpus da UNESP, verificou-se um rebaixamento médio de tamente aos valores diários pluviométricos do 1,23 m do NA (Figura 6). As variações observa- mesmo período, denota a existência de um desdas podem ser atribuídas a oscilações sazonais e compasso de aproximadamente 90 dias entre o atividades de bombeamento existentes na vizi- valor máximo de precipitação e o pico de ascennhança. O rebaixamento acentuado e a não recu- são do NA. Este tempo pode ser inferido como o peração do NA aos níveis iniciais do monitora- tempo de infiltração da água até a zona saturada mento podem ser explicados pelas baixas taxas do aquífero. Esse valor é muito próximo dos 87 pluviométricas do ano monitorado, cerca de 1000 dias calculados por Carnier Neto (2006). 


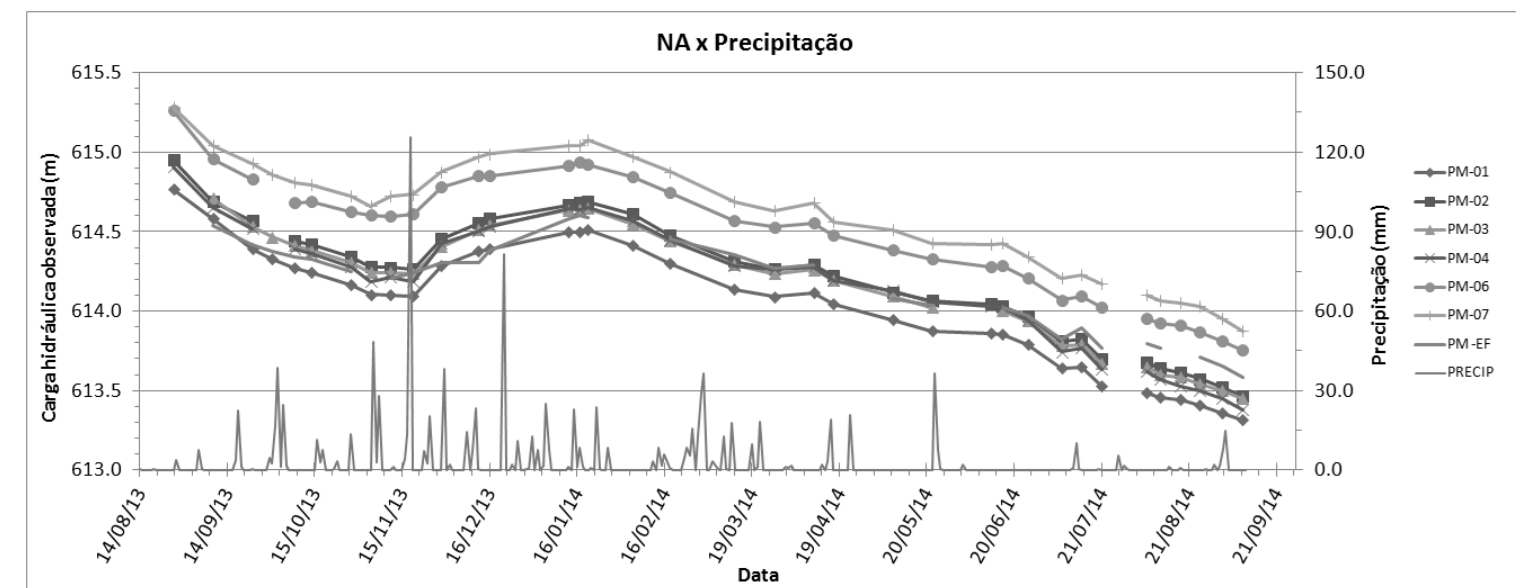

Figura 6 - Carga hidráulica e precipitação diária (mm) observadas ao longo de 365 dias, entre setembro/2013 e setembro/2014.

Figure 6 - Observed hydraulic head and daily precipitation rates (mm) throughout 365 days, between September/2013 and September/2014.

O resultado da análise textural das amostras coletadas indica uma grande variação na condutividade hidráulica do intervalo amostrado da Formação Rio Claro, como ilustrado na Figura 7. Esses valores serviram ao balizamen- to dos valores de condutividade hidráulica no modelo. Nota-se que o topo da Formação Corumbataí apresenta altos valores de condutividade, relacionados à sua alteração e à presença de fraturas no topo dessa unidade.

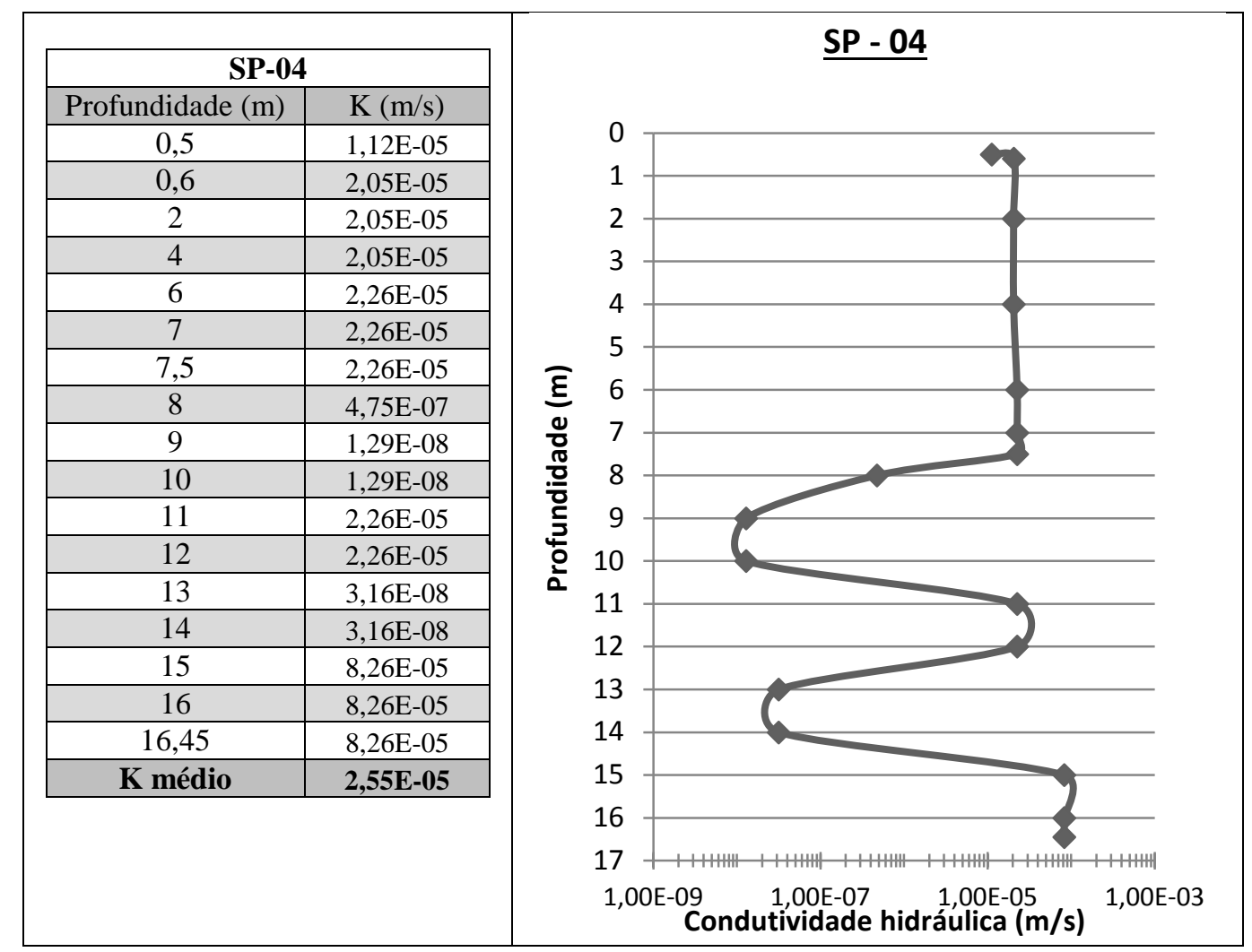

Figura 7 - Valores de condutividade hidráulica das amostras coletadas, obtidos pelo método indireto de Shepherd, e suas variações segundo a profundidade do furo.

Figure 7 - Hydraulic conductivity values of the collected samples measured by the indirect method of Shepeherd and their difference with the deep.

A Tabela 1 apresenta os resultados dos testes slug realizados em alguns PM do campus da UNESP. A heterogeneidade do Aquífero Rio Claro pode ser observada pela diferença de até 
Simulação numérica de fluxo de águas subterrâneas do aquífero rio claro, porção nordeste do município de Rio Claro, SP

duas ordens de grandeza entre os valores obti- $\quad$ tratados em ambiente SIG, em que se construiu dos nos testes, mesmo para poços próximos.

Os dados coletados em campo e reunio modelo numérico para o software FEFLOW $6.1^{\circledR}$, Tabela 2.

dos da revisão bibliográfica foram agrupados e

Tabela 1 - Valores de condutividade hidráulica obtidos através de testes SLUG em poços de monitoramento

Table 1- Hydraulic conductivity values acquired by SLUG tests in monitoring wells

\begin{tabular}{cc}
\hline Poço & Condutividade Hidráulica - m/s \\
\hline PM-01 & 2.93 E-05 \\
PM-02 & 1.40 E-04 \\
PM-06 & 1.73 E-06 \\
\hline
\end{tabular}

Tabela 2 - Dados reunidos da literatura e coletados no presente trabalho

Table 2 - Collected data from literature and from the present work

\begin{tabular}{|c|c|c|c|}
\hline \multirow{5}{*}{$\begin{array}{c}\text { Dados reuni- } \\
\text { dos da litera- } \\
\text { tura }\end{array}$} & \multicolumn{2}{|c|}{$\begin{array}{l}\text { Condutividade Hidráulica - Formação Rio } \\
\text { Claro }\end{array}$} & \multirow{2}{*}{$\begin{array}{c}\text { Contatos Geológicos } \\
\text { Zaine (2000) } \\
\end{array}$} \\
\hline & Referência & Valor (m/s) & \\
\hline & Cottas (1983) & $10^{-5}$ & Oliva (2006) \\
\hline & Yamada (2004) & $10^{-6}-10^{-4}$ & Perinotto et al (2006) \\
\hline & Oliva (2006) & $10^{-7}-10^{-4}$ & SIAGAS/CPRM (2014) \\
\hline
\end{tabular}

\begin{tabular}{c|cc|c}
\hline \multirow{2}{*}{$\begin{array}{c}\text { Dados coleta- } \\
\text { dos no pre- }\end{array}$} & \multicolumn{2}{|c|}{$\begin{array}{c}\text { Condutividade Hidráulica - Formação Rio } \\
\text { Claro }\end{array}$} & Poços de Monitoramento \\
\cline { 2 - 4 } sente trabalho & Método & Valor (m/s) & Condutividade Hidráulica \\
\cline { 2 - 4 } & Slug test $\begin{array}{c}\text { Shepherd (amostras } \\
\text { de } S P T)\end{array}$ & $10^{-6}-10^{-4}$ & Oscilações do NA \\
\cline { 2 - 4 } & \multicolumn{1}{c}{$10^{-8}-10^{-5}$} & Contatos Geológicos \\
\hline
\end{tabular}

\section{Modelo Numérico de Fluxo}

A construção do modelo numérico tem início com a definição dos contornos do domínio e a geração da malha. Ressalta-se que a área de interesse é o câmpus da UNESP, porém, o domínio modelado foi extrapolado em relação à área de interesse, a fim de se evitar instabilidades numéricas ocorridas principalmente nas bordas do polígono. O limite oeste do polígono foi definido pelo divisor de águas, enquanto as outras extremidades foram delimitadas por drenagens.

A malha de elementos finitos gerada possui uma área de $9,73 \mathrm{~km}^{2}$ e um volume de $0,26 \mathrm{~km}^{3}$ (Figura 8). O domínio foi discretizado em 318040 elementos triangulares, interligados por 203742 nós. A malha foi refinada nas bordas do polígono, nos PM e nas drenagens para evitar maiores instabilidades numéricas e aperfeiçoar os resultados nestes locais. Para o modelo tridimensional, seis camadas foram geradas em profundidade.
À primeira camada foram atribuídas as cotas do terreno, segundo mapeamento elaborado por Zaine (2000). Outras três camadas foram inseridas como representantes da Formação Rio Claro, com vistas à melhor distribuição dos diferentes horizontes de valores de condutividade hidráulica observados na unidade. A análise dos poços do SIAGAS/CPRM possibilitou também a identificação de soleiras de diabásio isoladas, as quais foram inseridas no modelo em suas respectivas profundidades.

Uma quarta camada representa o topo da Formação Corumbataí, contato impermeável do aquífero, obtido de dados geofísicos de Oliva (2006). Foram inseridas camadas justapostas a esta para a melhor representação do "efeito barreira" que a unidade causa na base do aquífero. Todas as camadas do modelo tiveram uma espessura mínima estipulada em 2,0 m para não haver instabilidades numéricas durante as simulações. 


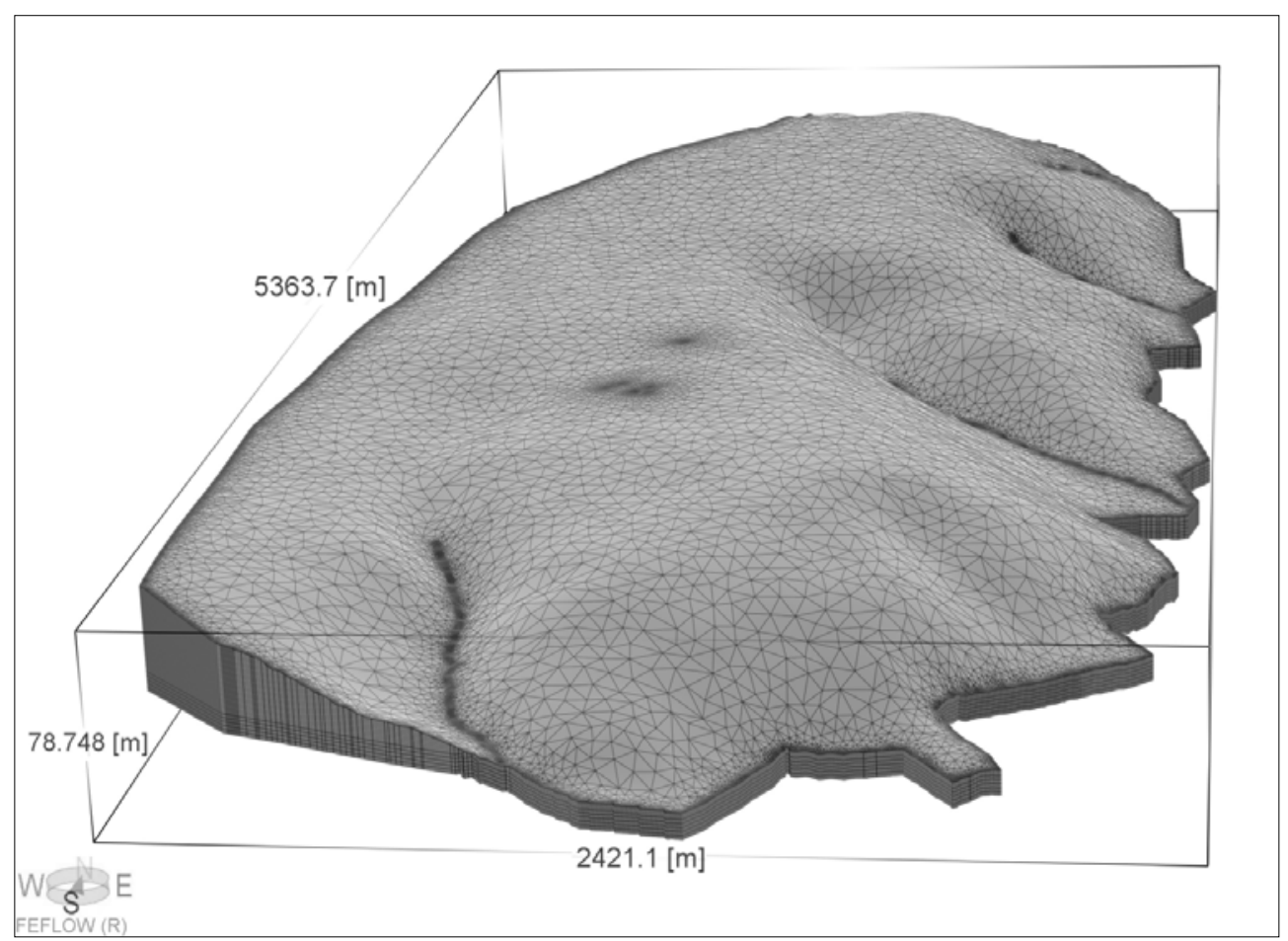

Figura 8 - Domínio simulado visto em três dimensões

Figure 8- Simulated domain in a $3 \mathrm{D}$ view

Os PM do câmpus foram colocados como pontos de observação para comparação dos resultados de carga hidráulica e cálculo do erro residual da simulação. As condições de contorno inseridas ao domínio foram todas de primeiro tipo (condição tipo Dirichlet), ou seja, de carga hidráulica especificada. Essa condição atribui um valor específico para a carga hidráulica num dado ponto e a resposta da simulação deve ser ajustada sobre essa imposição. Somente as drenagens com conexão direta com o aquífero, zonas de saída de água do sistema, foram consideradas para tal finalidade no modelo.

\section{Simulação em Regime Permanente}

O modelo em regime permanente foi construído e calibrado para servir de ponto de partida para a simulação em regime transiente. Desse modo, foram utilizados dados de NA do dia 09/09/2013 ( $\mathrm{t}=0$ dias) para calibração.

Inicialmente, os valores de condutividade hidráulica foram balizados pelos testes slug realizados e pelas amostras coletadas. Para a calibração do modelo, o método de "tentativa e erro" foi empregado, até que os valores de NA simulados estivessem mais próximos aos observados nos PM.

A Tabela 3 apresenta os valores de condutividade hidráulica obtidos após a calibração do modelo em regime permanente. Entende-se que o baixo valor da condutividade hidráulica da Formação Rio Claro deve-se às espessas lentes argilosas que ocorrem na unidade.

Acerca da recarga do aquífero, foram distribuídas diferentes zonas, segundo o uso e a ocupação do solo (Figura 9). Com a calibração, os valores ajustados ficaram entre $674 \mathrm{~mm} / \mathrm{ano}$, para áreas não pavimentadas e planas (áreas de recarga do aquífero), e $0 \mathrm{~mm} / \mathrm{ano}$, para áreas com cultura de eucalipto (altas taxas de evapotranspiração), drenagens (áreas de descarga do aquífero) e litotipos siltosos (infiltração nula). Na zona urbana foram admitidos valores de recarga comprometida, ou seja, 30\% do valor máximo, devido à pavimentação e a coberturas impermeáveis. 
Simulação numérica de fluxo de águas subterrâneas do aquífero rio claro, porção nordeste do município de Rio Claro, SP

Tabela 3- Valores de condutividade hidráulica após calibração do modelo em regime estacionário Table 3- Hydraulic conductivity values obtained after calibration of the steady state model

\begin{tabular}{cccc}
\hline Layer & Elemento & Principal Característica & K-xy (m/s) \\
\hline $\mathbf{1 - 2 - 3}$ & Fm. Rio Claro & Porção mais argilosa da formação & $9,0 . \mathrm{E}-6,0$ \\
& Fm. Rio Claro & Arenito com lentes argilosas dispersas & $5,5 . \mathrm{E}-5,0$ \\
& Fm. Corumbataí & Siltito com topo alterado e arenoso & $3,0 . \mathrm{E}-6,0$ \\
& Aluvião & Areia fina bem selecionada & $5,0 . \mathrm{E}-4,0$ \\
\hline $\mathbf{4}$ & Fm. Corumbataí & Siltito argiloso & $1,0 . \mathrm{E}-8,0$ \\
& Intrusão Diabásio & Baixos parâmetros hidrogeológicos & $1,0 . \mathrm{E}-8,0$ \\
\hline $\mathbf{5 - 6}$ & Fm. Corumbataí & Sitito argiloso & $1,0 . \mathrm{E}-10,0$ \\
& Intrusão Diabásio & Baixos parâmetros hidrogeológicos & $1,0 . \mathrm{E}-10,0$ \\
\hline
\end{tabular}
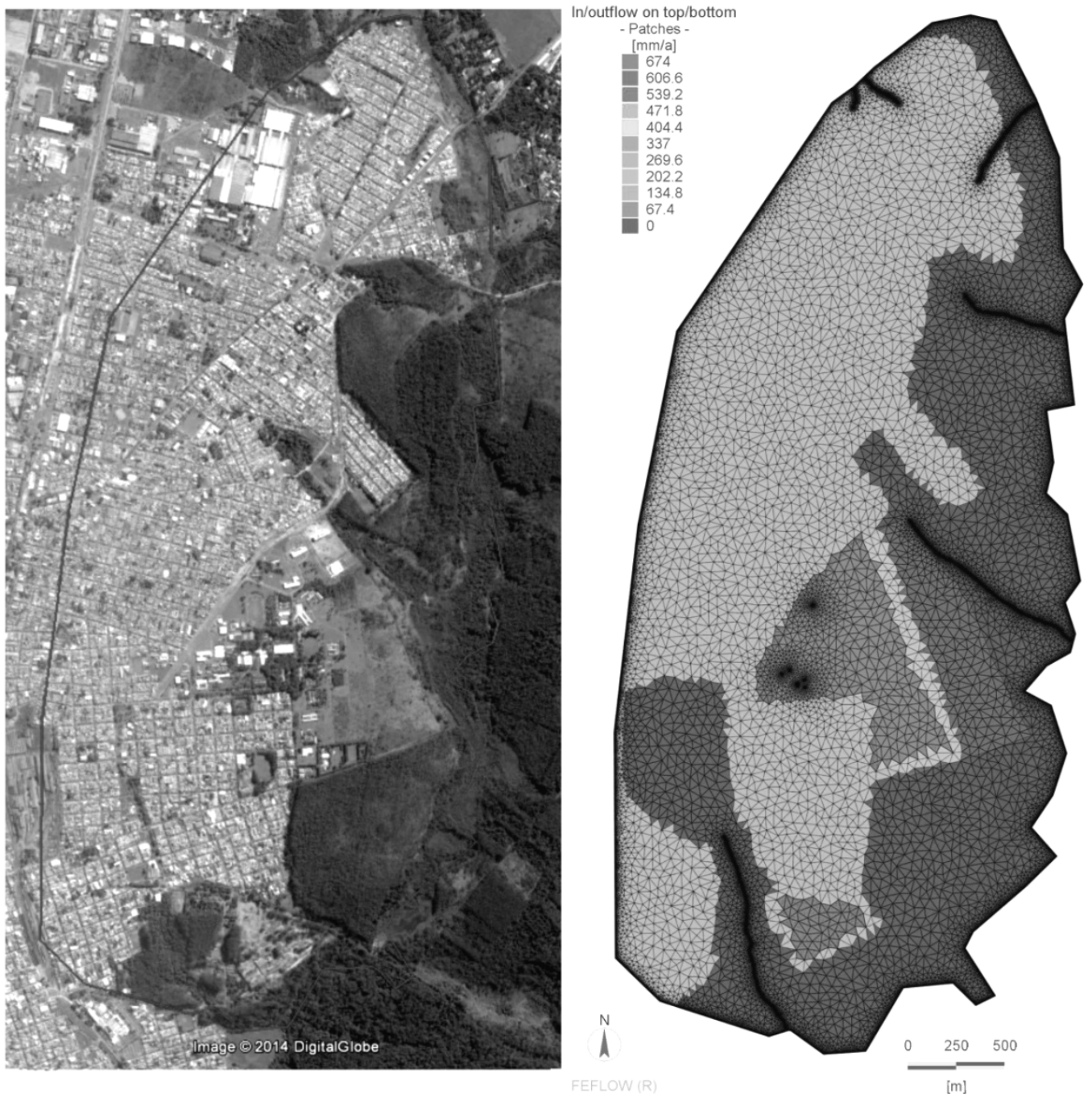

Figura 9- Distribuição das zonas de recarga segundo uso e ocupação da superfície do solo. Os maiores valores de recarga se encontram nas áreas do câmpus da UNESP

Figure 9 - Recharge zone distribution according the use and the occupation of the soil surface. The greater values of recharge are at the campus site 
O mapa potenciométrico gerado (Figura 10 ) indica um fluxo geral com sentido principal SSE, secundariamente em direção às drenagens mais próximas. Nota-se também que o fluxo segue a conformidade topográfica, com as maiores cargas hidráulicas nas maiores cotas da área, característica esta de aquíferos livres. A velocidade média de Darcy para o domínio simulado foi de $10-8 \mathrm{~m} / \mathrm{s}$, sendo ligeiramente maiores próximas às zonas de descarga.

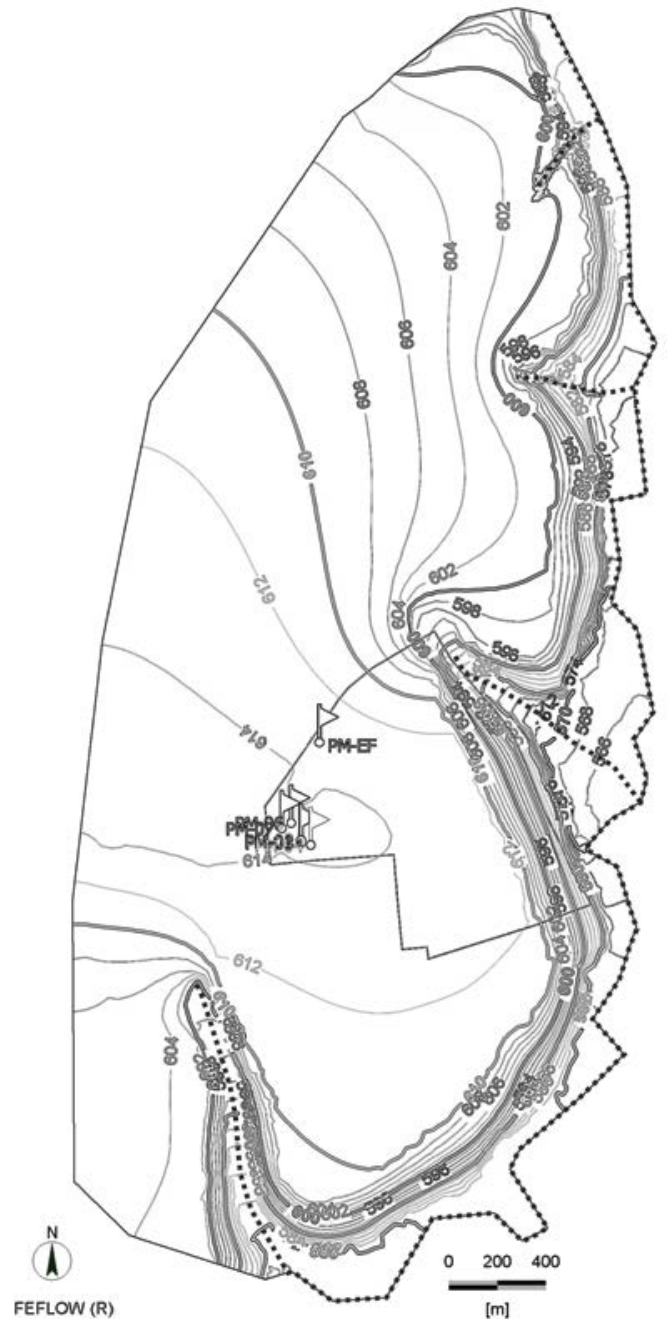

Figura 10 - Mapa potenciométrico, com destaque para a área do câmpus da UNESP, poços de monitoramento e drenagens da área (linha pontilhada)

Figure 10- Potentiometric map, highlighting the area of the campus of UNESP, the monitoring ells and the streams of the area (dashed lines)
A Figura 11 apresenta o gráfico de dispersão dos valores de carga hidráulica da simulação em regime permanente em relação aos valores observados. Salienta-se o baixo erro obtido entre os valores simulados e observados e o valor do RMS (Root Mean Square) normalizado de apenas $8,47 \%$.

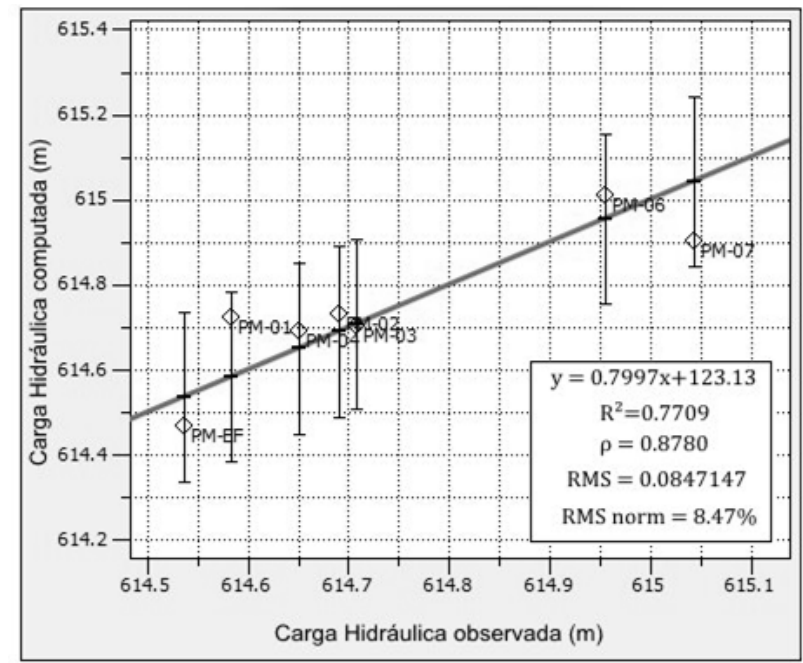

Figura 11- Dispersão da Carga Hidráulica da simulação em regime permanente e os respectivos coeficientes de correlação e determinação RMS e $\mathrm{R}^{2}$

Figure 11- Hydraulic head dispersion of the simulation in steady-state conditions and its correlation and determination coefficients RMS and $\mathrm{R}^{2}$

\section{Simulação em Regime Transiente}

Nesta etapa, os parâmetros hidrogeológicos obtidos em regime permanente são mantidos constantes. O único parâmetro variável é a recarga, já que apresenta variações sazonais que devem ser representadas.

Os parâmetros foram calibrados até a obtenção de um comportamento do NA análogo ao observado no ano monitorado. A Tabela 4 traz os valores de carga hidráulica para o último estágio da simulação e a diferença entre os valores. A maior diferença, de apenas $0,81 \mathrm{~m}$, foi encontrada no poço PM-01. 
Simulação numérica de fluxo de águas subterrâneas do aquífero rio claro, porção nordeste do município de Rio Claro, SP

Tabela 4 - Valores de carga hidráulica observados e calculados para cada poço no último estágio da simulação e a diferença entre eles

Table 4 - Hydraulic head values observed and calculated for each well in the last stage of the simulation and the difference between them

\begin{tabular}{cccc}
\hline Poço & $\begin{array}{c}\text { Carga Hidráulica } \\
\text { observada }(\mathbf{m})\end{array}$ & $\begin{array}{c}\text { Carga Hidráulica com- } \\
\text { putada }(\mathbf{m})\end{array}$ & Diferença (m) \\
\hline PM-01 & 613.316 & 614.1324 & 0.8164 \\
PM-02 & 613.461 & 614.1351 & 0.6741 \\
PM-03 & 613.451 & 614.1256 & 0.6746 \\
PM-04 & 613.375 & 614.1232 & 0.7482 \\
PM-06 & 613.753 & 614.2316 & 0.4786 \\
PM-07 & 613.872 & 614.2418 & 0.3698 \\
PM-EF & 613.769 & 613.6572 & -0.1118 \\
\hline
\end{tabular}

O balanço hídrico calculado aponta a saída de água para as drenagens (4 142830 m³), com contribuição secundária dos poços de bombeamento (50 $370 \mathrm{~m}^{3}$ ) (Figura 12). A razão Recarga/Precipitação calculada pela simulação foi de $13 \%$. Esse valor corresponde ao volume de água de chuva que percola pela zona insatu- rada e atinge a zona saturada do aquífero. O remanescente desse volume (87\%) fica retido na zona vadosa ou deixa o sistema por run-off e evapotranspiração. Uma vez suprimida a precipitação, não haveria recarga do aquífero e o NA se rebaixaria de forma drástica.

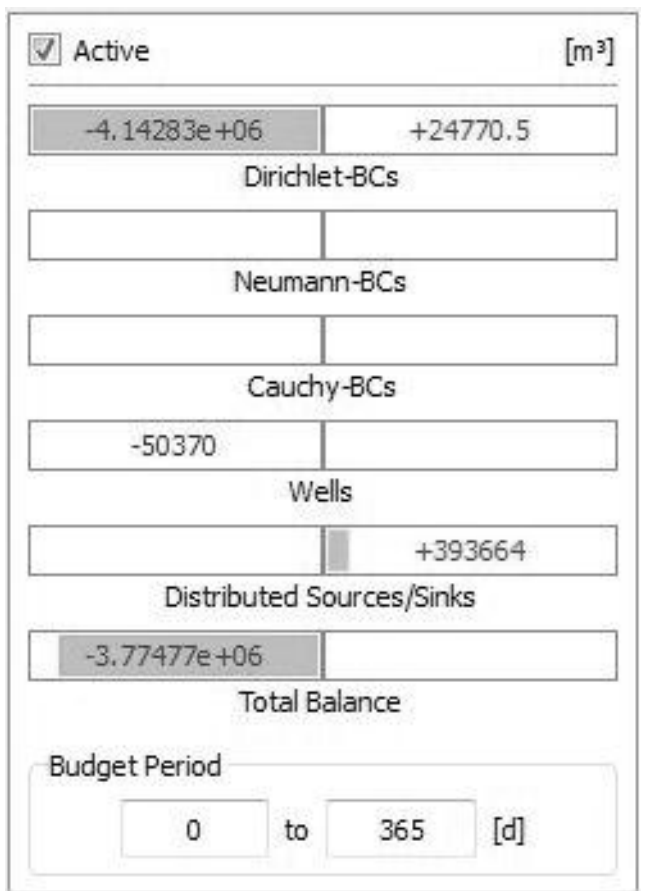

Figura 12 - Balanço hídrico do sistema após 365 dias de simulação. O sinal negativo representa saída de água, e o positivo, entrada de água no sistema

Figure 12 - Water balance of the system after 365 days of simulation. The negative sign shows water outlet and the positive shows water entering the system

Verifica-se que a recarga provém majoritariamente de águas pluviais (> 95\%), com ínfima contribuição das drenagens locais $(<5 \%)$, ocorrendo principalmente entre os meses de dezembro e fevereiro, entre $t=60$ dias e $t=130$ dias (Figura 13). Comparando-se com a Figura 6, observa-se comportamento análogo entre o NA simulado e o observado. 


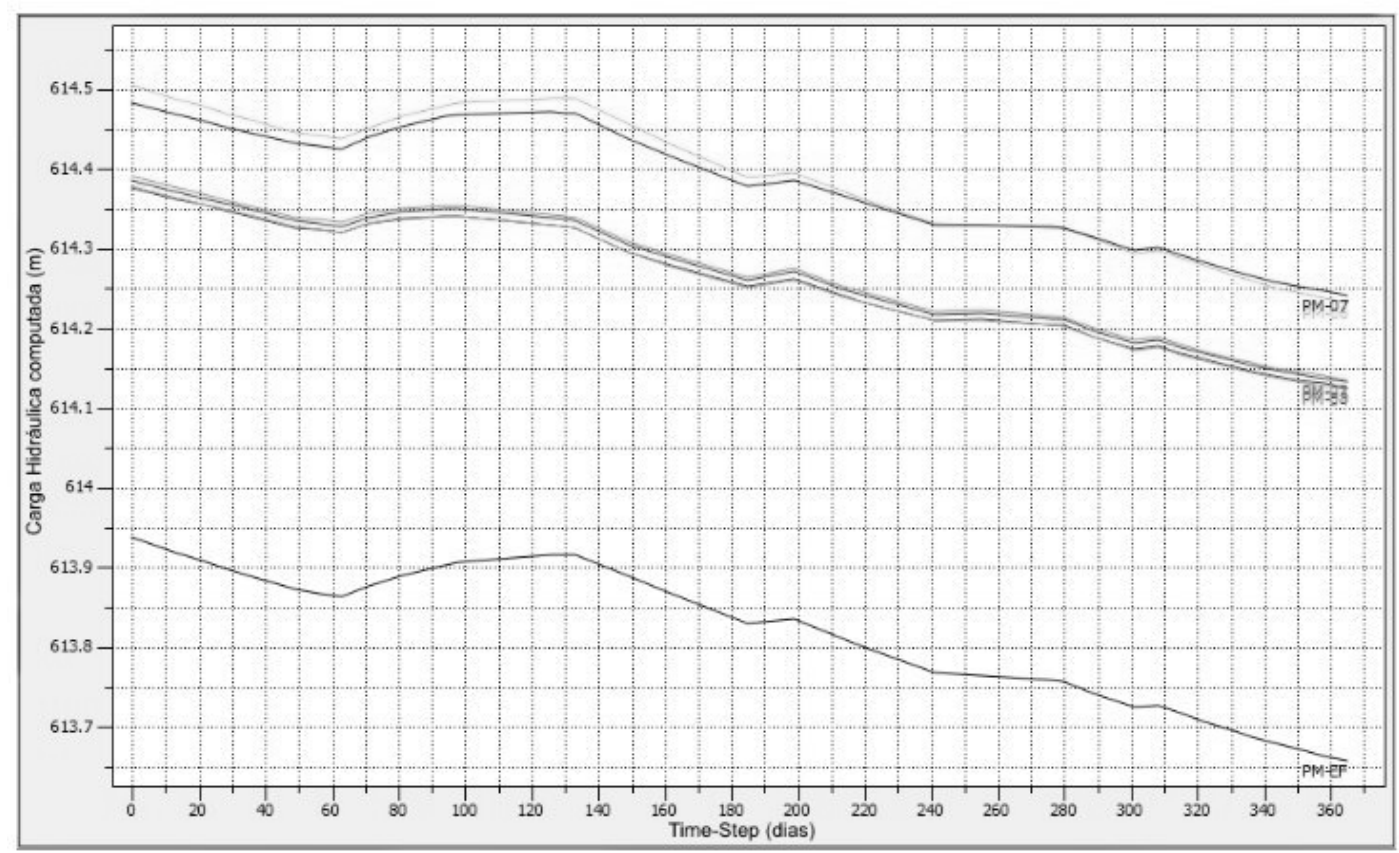

Figura 13 - Carga hidráulica simulada nos poços de monitoramento ao longo de 365 dias de simulação. Figure 13 - Simulated hydraulic head on the monitoring wells throughout 365 days of simulation.

Devido à alta heterogeneidade do aquífero e à frequência de intercalações argilosas, o valor médio do armazenamento específico foi calibrado abaixo da média para litotipos semelhantes. Tal fato foi reforçado pela análise do furo SPT (SP-04), no qual as porções argilosas perfazem $35 \%$ da seção, diminuindo o valor médio ponderado do parâmetro de armazenamento específico em até $65 \%$.

Os resultados da dispersão da carga hidráulica do último estágio (time-step) simulado no regime transiente são apresentados na Figura 14. Esses resultados mostram que o valor do RMS aumentou com a progressão da modelagem, enquanto o fator de correlação diminuiu, indicando um modelo ligeiramente instável. Apesar disso, os resultados são interpretados como satisfatórios, devido à distribuição não homogênea dos PM e ainda às incertezas que perduram sobre parâmetros de entrada, como, por exemplo, o controle da recarga.

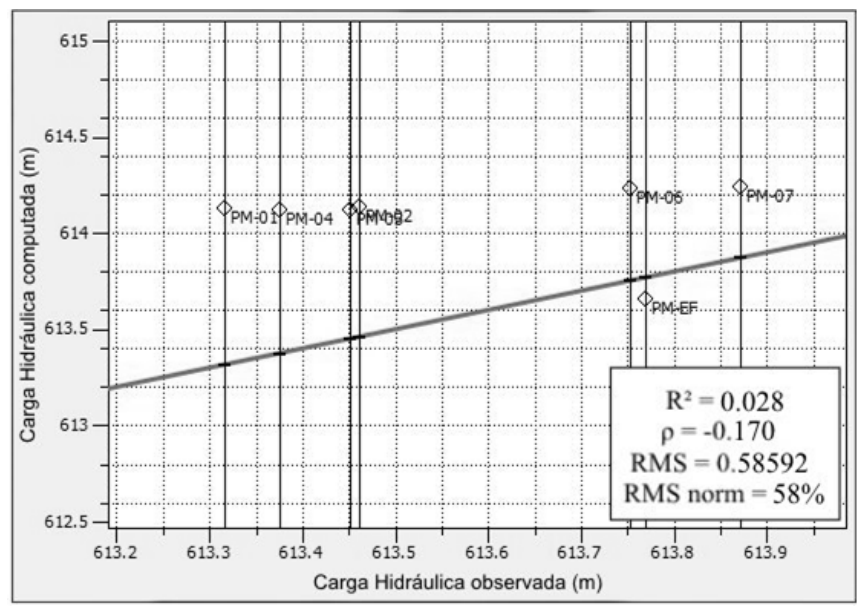

Figura 14 - Dispersão da Carga Hidráulica no último estágio simulado e os respectivos coeficientes de correlação e determinação RMS e R²

Figure 14- Hydraulic head dispersion at the last simulated stage and its correlation and determination coefficients RMS and $\mathrm{R}^{2}$ 
Simulação numérica de fluxo de águas subterrâneas do aquífero rio claro, porção nordeste do município de Rio Claro, SP

A relação entre a velocidade do fluxo das águas subterrâneas e as conformidades geométricas do domínio permite inferir o tempo e o percurso da água no aquífero. Com a ferramenta de projeção de traçadores dentro do domínio simulado, foi possível a aproximação do tempo de residência da água no aquífero, calculado em 5000 dias desde as áreas de recarga até as zonas de descarga.

\subsection{Análise de Sensibilidade}

A análise de sensibilidade foi efetuada para identificar o grau de dependência do modelo frente às mudanças nos parâmetros de entrada. Foram aplicadas alterações de $20 \%$ nos parâmetros de entrada, observando o coeficiente de sensibilidade $\boldsymbol{S}$ obtido:

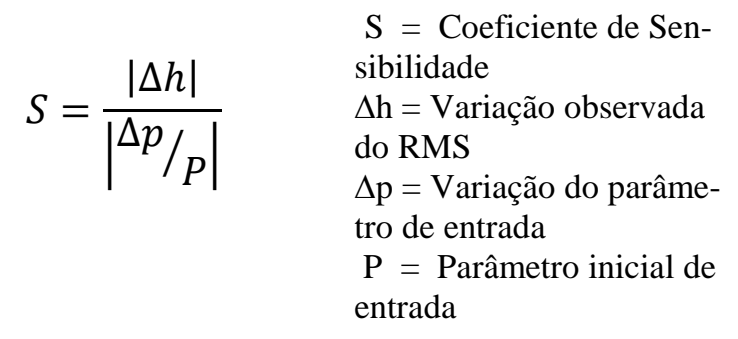

Quanto maior esse coeficiente, maior o grau de dependência do modelo àquele parâmetro específico e maior é a incerteza a ele agregada. A Tabela 5 apresenta os coeficientes da análise de sensibilidade obtidos na modelagem.

Tabela 5 - Coeficientes de sensibilidade para as mudanças aplicadas aos diferentes parâmetros do modelo e o valor de RMS obtido nas simulações

Table 5 - Sensitivity coefficient values for the changes applied to the model and the RMS value obtained on the simulations

\begin{tabular}{ccccc}
\hline Parâmetro & $\begin{array}{c}\text { Variação do } \\
\text { Parâmetro }\end{array}$ & RMS original & $\begin{array}{c}\text { RMS alte- } \\
\text { rado }\end{array}$ & $\begin{array}{c}\text { Coeficiente de } \\
\text { Sensibilidade, } \boldsymbol{S}\end{array}$ \\
\hline Porosidade efetiva & $20 \%$ & 0.58592 & 0.60672 & 0.1040 \\
Recarga & $20 \%$ & 0.58592 & 0.61304 & 0.1356 \\
Armazenamento específico & $20 \%$ & 0.58592 & 0.63560 & 0.2484 \\
Poços de bombeamento & $100 \%$ & 0.58592 & 0.65176 & 0.2957 \\
\hline
\end{tabular}

Com vistas a auxiliar na gestão hídrica do aquífero na área, foram simulados cenários com a duplicação da taxa de explotação dos poços que se encontram em atividade no câmpus. O coeficiente de sensibilidade obtido $(0,296)$ mostra que esse aumento implicaria em pequenas alterações no sistema, com aumento de até 8\% na saída de água, observada no cálculo do balanço hídrico final.

\section{CONCLUSÃO}

A aplicação de modelos numéricos em hidrogeologia tem sido uma ferramenta de grande auxílio para a representação de formações geológicas e estruturas complexas, bem como na melhor interpretação dos processos que ocorrem no aquífero. O software FEFLOW $6.1^{\circledR}$ mostrou-se adequado à representação do Aquífero Rio Claro, bem como acessível em sua interface de uso e na manipulação dos dados.

Com a modelagem foi possível identifi- car os parâmetros e as características de maior incerteza do sistema modelado. Verifica-se que a condutividade hidráulica está diretamente relacionada à distribuição dos litotipos presentes, bem como às velocidades do fluxo. Devido às frequentes intercalações argilosas na unidade aquífera, o parâmetro de armazenamento específico foi pautado abaixo da média para formações de mesma litologia, o que pode resultar em um menor volume de água armazenado pelo sistema. É ainda possível afirmar que as simplificações do arcabouço geológico local não foram fator limitante para a representação do sistema (aquífero), podendo ser dividido em zonas de homogeneidade hidráulica.

Os resultados obtidos são representativos, não obstante as condições reais da área, como a distribuição complexa dos litotipos argilosos e o baixo gradiente no local, além da distribuição irregular dos poços de monitoramento. Os resultados da modelagem permitiram a reprodução do comportamento de sistema análogo ao observado em campo, servindo de 
auxílio na interpretação de cenários hipotéticos e ainda na gestão do aquífero.

O monitoramento do NA e as simulações efetuadas apontam para uma possível depleção do aquífero, uma vez que os regimes pluviométricos e hídricos continuem os mesmos do período observado. Esse fato é reforçado pela acentuada queda do NA nos poços de monitoramento, além da não recuperação do mesmo aos níveis iniciais observados após um ano hídrico completo.

\section{REFERÊNCIAS}

CARNIER NETO, D. Análise das Séries Temporais de Monitoramento de Nível d'Água em Poços no Aquífero Rio Claro, (Dissertação de Mestrado). Universidade Estadual Paulista, Instituto de Geociências e Ciências Exatas, Rio Claro (SP). 88 p., 2006.

COTTAS, L.R. Estudos geológico-geotécnicos aplicados ao planejamento urbano de Rio Claro - SP. 171 p., 2v. Tese (Doutorado) - Instituto de Geociências, Universidade de São Paulo, São Paulo, 1983.

CPRM - Serviço Geológico do Brasil. Geologia e Recursos Minerais do Estado de São Paulo. Escala 1:750.000. 2002.

EL-KADI, A.L. Groundwater Models for Resources Analysis and Management. Florida: CRC/Lewis Pub., 1995.

FREEZE, A.; J. A. CHERRY. Groundwater. Prentice Hall, Inc., Eaglewood Cliffs, New Jersey, 604 p., 1979.

OLIVA, A. Estudo Hidrofaciológico do Aquífero Rio Claro no Município de Rio Claro - SP. (Tese de Doutorado), Universidade Estadual Paulista, Instituto de Geociências e Ciências Exatas, Rio Claro (SP). 196 p., 2006.

PERINOTTO, J. A J. et al. Nova Contribuição ao Conhecimento da Formação Rio Claro (T) na Folha Rio Claro (SP), Geociências, v.25, n.3, p.297-306, 2006.

SIGRH - Sistema de Informações para o Gerenciamento de Recursos Hídricos do Estado de São Paulo. Disponível em: <www.sigrh.sp.gov.br>. Acesso em:

15 abr. 2014.

\section{AGRADECIMENTOS}

Os autores agradecem ao Laboratório de Estudo de Bacias (LEBAC)/IGCE/UNESP, associado ao Centro de Estudos Ambientais (CEA)/UNESP e a seus colaboradores e pesquisadores pelo apoio recebido na realização deste trabalho. CHK agradece ao $\mathrm{CNPq}$ (Proc. 303330/2011).

STOLLBERG, R. Groundwater Contaminant Source Zone Identification at an Industrial and Abandoned Mining Site - A Forensic Backward-In-Time Modelling Approach. (Tese de Doutorado), Martin Luther University Halle-Wittenberg, Germany, 203 p. 2013.

TERAMOTO, E. H. Caracterização hidrogeológica e simulação numérica de fluxo em uma região situada no Distrito Industrial de Paulínia (SP). (Tese de Mestrado), Universidade Estadual Paulista, Instituto de Geociências e Ciências Exatas, Rio Claro (SP). 95 p., 2007.

YAMADA, D. T. Caracterização geológico-geotécnica aplicada à instalação de postos de combustíveis em Rio Claro (SP). Rio Claro: UNESP. Dissertação (Mestrado). 122f. - Instituto de Geociências e Ciências Exatas, Universidade Estadual Paulista, 2004.

ZAINE, J. E. Geologia da Formação Rio Claro na folha Rio Claro (SP). (Dissertação de Mestrado) - Instituto de Geociências e Ciências Exatas, Universidade Estadual Paulista, Rio Claro (SP), 90p, 1994.

ZAINE, J. E. Mapeamento Geológico-Geotécnico Por Meio Do Método Do Detalhamento Progressivo: Ensaio De Aplicação Na Área Urbana Do Município De Rio Claro (SP). (Doutorado em Geociências) - Instituto de Geociências e Ciências Exatas, Universidade Estadual Paulista, Rio Claro (SP), 149 p., 2000.

ZHENG, C., \& G.D. BENNETT, 1995, Applied Contaminant Transport Modeling: Theory and Practice, Van Nostrand Reinhold (now John Wiley \& Sons), New York, 440 pp. 